towards the observer he does so without trouble. He states, too, that he is a good swimmer. These two facts are difficult to reconcile with the apparent incapacity to move his arms with closed eyes. Again, if with closed eyes his arms and fingers are extended and any small light object be placed in one hand, and a much heavier object (such as a heavy iron bar or a solidly-made wooden chair) be placed in the other, and he then be told to close his fingers-a movement which he performs with apparent difficulty-he is incapable of saying which hand holds the heavier weight, he is quite ignorant of the nature of the objects, and most frequently he is unconscious of the fact of anything having been placed in his hands. If an object held in the hand be very bulky and if the fingers be closed very forcibly on it he is generally able to say that there is something in his hand without knowing what. He appears ignorant of the meaning of fatigue, and asserts that the only means by which he is made aware of his failing strength, under any intense or prolonged effort, is by his falling to the ground.

The sense of position is equally absent. With eyes closed he is unable to bring the tips of the index fingers into contact, to touch the tip of his nose with a finger, or to locate his hand when placed by the observer in any given position. If asked to raise his hand from its position resting on his knee and to touch his head, his eyes being closed, he appears completely nonplussed, and, as noted above, responds only by slight jerkings of the hand. With visual control all his movements are perfectly coördinated and in every way normal.

He exhibits the phenomenon of the fixation of the limbs in the positions in which they are placed. Thus, the patient is placed on his back with arms stretched out by the sides, and legs extended. The eyes are closed. If now the observer takes the patient's limbs and places them in any position (for example, both arms raised in the air above the head, and one leg raised with the thigh flexed and the knee bent), he is totally unaware of having been touched or of any change of position in his limbs, and the arms and legs remain fixed where they have heen placed without conscious muscular effort on the part of the patient. Or opening his eyes he manifests genuine surprise at his attitude.

Sense of taste. - Completely absent. The patient's eyes being closed, about half a drachm of such substances as sugar, salt, pepper, mustard, also a drop or two of an essential oil (oil of cloves), were in turn placed upon his tongue, and each in turn thoroughly insalivated, and finally swallowed, but all failed to produce any sensation of taste, the patient being unconscious of any substance in the mouth. It may be remarked that he eats anything, as the fancy takes him. On one occasion he was found to have consumed a lump of bath-brick about the size of a hen's ege that a hospital orderly had inadvertently left in his way. He states that he is in the habit of eating uncooked-when he can get hold of them-such animals as rats, mice, dog, or serpent.

It appears that he is never conscious of hunger or thirst. It was not practicable under the circumstances to put this statement to the test, but he relates that for a bet he once refrained from food and drink for eight days and nights. He felt no inconvenience beyond, towards the end of the period, an abnormal tendency to sleep. At the completion of the fast he asserts that he returned to work in no way harmfully affected, and not conscious of any special craving for food or drink. This is recorded without guarantee as to its truth, as it was related by the patient.

Sense of smell.-Practically non-existent. Such characteristic odours as those of the oils of cloves, cinnamon, peppermint, the tincture of orange failed to produce any sensation. Fuming nitric acid was equally ineffective when strongly inhaled. On the other hand, the fumes of the strong solution of ammonia and of pure hydrochloric acid produced a faint sensation of an odour which the patient remembered to have smelt in his youth.

Reflooes. - The only response on both sides to plantar irritation was slight abduction of the little toe. The patellar reflexes were present and normal. The orbicularis palpebrarum muscles contracted on touching the cornea, though no sensation was evoked. The pupils reacted to light and accommodation.

Defacotion - The bowels usually act regularly once a day. There is no conscious desire to defæsate beyond what he describes as an occasional "rolling" in the abdomen. He never exerts any effort, nor is there knowledge of the passage of the fæces. Only when there is looseness of the bowels is there any incontinence.

Mioturition.-Ordinarily this occurs during action of the bowels once in 24 hours at about 8 o'clock in the morning. He asserts that usually he does not again micturate till the same time on the following morning, but as a precaution he generally gives himself the opportunity to pass urine at about 4 o'clock in the afternoon as well, but often without result. Only in the event of his taking more fluid than usual and failing to take the precautions he has learnt by experience to be necessary is there incontinence of urine. There is never desire to micturate.

Finally, he seems to be without most of the common emotions. He is without family affection-the fact that he believed his mother to be dying in no way disturbed him. He makes neither friends nor enemies. He has no love of country or home. But he would appear to be a smart and efficient soldier and takes a pride in it. He was always very active, ready, and willing to help in hospital duties.

Diagnosis. - A few words may be said as to diagnosis The most satisfying explanation of the thermic insensibility would be the existence of syringomyelia. The fact that the condition of the patient is practically congenital is com. patible with the developmental nature of the spinal lesion in this disease. It may be objected that the motor system is so far unaffected, but the course of the disease is well known to be very slow. Osler, in his " Practice of Medicine," notes one of the types of syringomyelia descrioed by Schlesinger in his monograph (1895) to which this case would in some measure conform-" with predominant sensory features, simulating hysterical hemiplegia, or with general pain and temperature anesthesia." At the same time there are certain inconsistencies in the clinical picture which point to a possible admixture of hysteria. He is a good swimmer, which implies the performance of regular coördinated movements of the legs without visual control. Yet on being invited to perform movements of the arms with closed eyes he was completely at a loss. He was also able to walk with eyes shut. The diagnosis of syringomyelia combined with hysteria is therefore suggested as one which seems to meet the case.

\section{THE PREVENTION OF RELAPSE OF HYSTERICAL MANIFESTATIONS.}

\author{
By T. A. ROSS, M.D. EDIN.,
}

TEMP. CAPTAIN, R.A.M.C., MEDICAL OFFICER IN GHARGE OF A DIVISION AT SPRINGFIELD WAR HUSPITAL.

THE first essential in the treatment of hysterical manifestations is accurate diagnosis, as has been pointed out by Fearnsides and others. ${ }^{1}$ Without going over the debatable question of reflex paralysis described by Babinski and Froment, it is necessary to remember that many patients who present hysterical manifestations show signs of organic lesions also. In many whose chief symptoms have a psycho. logical origin, readily removed by psychical treatment, a gross organic lesion is present, situated anywhere between the cerebral cortex and the periphery, giving rise to less prominent manifestations, and naturally remaining uninfluenced by psychical treatment. Putting aside theie cases, and they form by no means a small percentage of the total admissions to every hospital at which cuses of functional nervous disorder are treated, and dealing only with those patients in whom the manifestations are wholly of functional or "hysterical" origin, the question arises whether the removal of the obvious symptoms is the same as the "cure" of the patient; on clinical grounds it is certain that the two are not identical.

For the first few days after the removal of gross objective disabilities, patients, who have been admitted suffering from a functional nervous disorder, are usuallo genninely pleased; they have a sense of increased well-being and are deeply grateful. Later, however, many complain that they are not feeling so well. If asked how they are, many will say " My head is bad," although headache may not have been a symptom previously complained of ; or they may reply that they do not feel so well in general condition as when they were admitted. When making inquiries of this sort it is needless to say that care must be taken not to suggest to the patient any symptom, such as headache. But if the patient be asked in the most general terms how he is, especially if the question be put in a cheerful tone, in a manner which anti- 
cipates a favourable reply, it cannot be said that any suggestion has been made. Now it is undoubtedly true that the majority of medical men who treat and rapidly remove hysterical symptoms by methods which depend on some form of suggestion alone, hold a contrary view. They teach that the "cure" of the symptom is usually followed by improvement in general well-being. From a study of the published works of those who hold this view it may be assumed that the explanation of this discrepancy is, that after the symptom has been removed, these authors do not apparently thınk it wise to question the patient further. Contrary to what is asually believed, if the neuropath be not questioned, the doctor will not be told much; these patients do not talk about their symptoms to those whom they do not consider interested. A recent writer ${ }^{2}$ has even gone so far as to state that "there is no such thing as hysteria apart from hysterical symptoms." One holding this view could hardly be expected to probe far, after such symptoms were removed. In another work dealing with the rapid cure of hysteria by persuasion ${ }^{3}$ the same author states that "so far as we know relapses have not occurred after discharge (from hospital) except during air raids among men living in London. This is an additional argument, if any are still necessary, for the removal of all patients, officers as well as men, suffering from war neuroses out of L'ondon." It is, however, more than possible that it is an argument that the method of persuasion which this author employs is inadequate, and indeed an argument that there is something in hysteria besides the symptoms.

The removal of hysterical symptoms in these war cases is not difficult. Any doctor who will take the trouble to listen attentively to the whole story which the patient tells, who makes a careful, complete clinical examination, who is able to make up his own mind defiaitely that the spmptoms have a functional origin, and who then so expresses himself that the patient becomes aware of all this, will be rewarded by the speedy disappearance of these symptoms. Some doctors seem to be fortified by the use of aids such as electricity, hypnotism, or manipulations; others by making the patient half drunk. But none of these things are necessary, and in the end most of them are hirmfal. The simple explanation that it is want of confidence on the patient's own part which is keeping the symptom still in existence, and very quiet directions telling him what to do will suffice, provided that all the foregoing conditions are observed.

At this stage, however, the pitient is not cured. $\mathrm{He}$ is not yet cured because that which underlay the hysterical manifestation has not yet been touched. Two undesirable happenings may ensue : either $(a)$ the patient may begin, or continue, to complain of other symptoms, such as hea lache, or (b) during some time of emotional stress, such as an air raid in London, the symptoms may reappear. Much can bedone for the latter contingency by prophylactic education. Every patient should be instructed that in the future, and at any time. his symptoms may return as an emotional reaction. Should this happen, and he recognises that it is analogous to a transitory flood of tears, it will not persist, and little inconvenience will be caused. If, on the other hand, he thinks that the dread disease has returned because he was not fully cured. the want of confidence which such a thought engenders may prolong the reaction indefinitely. Then his state will be as it was before the "cure."

G. R., after an attack of "trench fever," suffered from tremors so gross as to prevent him walking. He was treated for several weeks in France with rest in bed; then he was evacuated to England, and in a single hour the tremor and difficulty in walking were "cured" by persuasion, but no explanation was given. Two months later he retarned to his depôt. There he immediately collapsed and remained in a state of complete astasia-abasia till he could obtain further treatment.

This case may be contrasted with that of $\mathrm{D}$. MoH., who was admitted to hospital suffering from a flaccid, hysterical paraplegia. He was cured by persuasion, and the nature of an affective response was explained. One night a few weeks later there was an air raid. The patient wanted to get up in order to go to the subway, to which any patient may proceed on such occasions. To his surprise be was unable to move his legs. Remembering what he had been told, he thought for five minutes of the explanation, which to him had been given previously; then be got up and walked to the subway.

An air raid and a return to depôt are both events associat ed with emotion; he who cannot stand the one is not likely to stand the other. For the success of the method, the means employed must be of the simplest. The man must be convinced that it was he himself who worked the "cure," or he cannot hope in future to "cure " himself. It is impossible to make use of this method if the man has been treated with electricity or manipulations, \&c. For then he is certain to believe that it was the "agent" which effected the " cure." But if all that the medical officer did was to tell him that he was able to talk or to walk, and he thereapon did so, he can reasonably hope to repeat the "cure" by himself if necessary. Experience proves that he usually can do this. Care must be taken that the "cure" does not occur whilst the patient is being so much as touched. Thus a dumb man unfortunately recovered his speech while his throat was being examined with a laryngoscope. This patient relapsed, and was unable to "cure " himself because he believed that the mirror had been the instrument of "cure," and that the use of some objective apparatus was essential.

A better way to prevent relapse, better because it deals also with the concomitant symptoms, is to find out why the patient ever had an hysteri al symptom at all. There is something in hysteria besides the symptoms; there is evidently some special tendency for the patient to react in this abnormal way; there is always a series of other symptoms, such as headache, insomuia. \&c. The individual is out of harmony with his environment, and inquiry will show that the mal-adaptation is psychical. He has some trouble, and this must be brought to the surface. The object of this is simple. When two people discuss a difficulty, a reasonable view of it is more likely to be taken than when it is brooded over alone. After such a discussion the patient looks at his trouble in a different and happier way. Moreover, some idea may be brought to light, some thought which had determined the form taken by the hysterical manifestation, and this will impress on him the more how he $m+y$ become the master of his health.

A. D. had total paralysis of the right arm, which hung like a flail by his side. It had come on suddenly one morning at dawn eight months previously; he had been on duty all night in an observation post, and had just been relieved. He was climbing out of the post, using this arm to pull him self over a parapet, when the arm became paralysed and he fell back into the trench. He could not account for it in any way. By a process of thinking back he was soon able to recollect what had been in his mind at the moment the arm gave way-viz., that this moraing was lighter than usual, and that he might be seen and sniped. The proof that the symptom had oscurred, not as a result of disesse, but as a pure "defence," was now made very elear to the patient, who returned to duty in a few weeks.

Not always will anything so striking as this be discovered, but with careful inquiry some point of psychical importance will be found, most often of a nature which has caused wain to the patient-fear that he has been a coward, that he will become insane, that he will suffer much disability in future-needing only discussion to be dissipated. To obtain this information time and patience are essential ; most of it can be got by ordinary conversation, and the proper taking of the history. The best description of the way in which this should be done will be found in Déjerine and Gauckler's Psychotherapy. ${ }^{4}$ Rarely will it be necessary to employ more difficult methods than those there laid down for these matters have not as a rule been so pushed out of consciousness that ordinary conversation will not reveal them. With patience events that have not been thought of for as many as 20 or 30 years may be brought to light. Should, however, this simple method fail we need not be afraid of psycho-analysis. We shall not as a rule, unless we are looking for them, be troubled with distressing sexual matters, as Rivers has shown. ${ }^{5}$ The method is, however, rarely needed ; time and gentleness yield an amount of information incredible till they have been tried.

When we have relieved the patient's mind by getting him to see his trouble in a different light it will be found that his capacity to withstand emotional reactions. such as those brought about by air raids, thunder, or the return to duty, has so much increased that he no longer meets them by the feeble defence of an hysterical symptom.

I have to thank Major R. Worth, R.A.M.C., for permission to quote the cases mentioned in this paper.

References.-1. Proceedings Roy. Snc. Med., April, 1918. 2. Medical Diseases of the War, Major A. F. Hurst. 3. THE LANCET, 1918, il. 240, Major Hurst. 4. Psycho-therapy, Déjerine and Gauckler. 5. The Layoert, 1917, i1., Captain W. H. R. Rivers. 